\title{
Why CCS? \\ Milestone on Research and Regulation Coverages
}

\author{
Aisyah Kusumaab*, Eko Widianto ${ }^{c}$, Rachmat Sule ${ }^{b}$, Wawan Gunawan A. Kadir ${ }^{b}$ \\ and Mega S. Gemilangd \\ a PT Pertamina Geothermal Energy, Menara Cakrawala lt 11, Jl. MH. Thamrin No.9, Jakarta 10340, Indonesia \\ ${ }^{b}$ Institut Teknologi Bandung, Indonesia \\ c Trisakti University, Indonesia \\ d PT Petro Teknologi Konsultan, Indonesia
}

\begin{abstract}
Further to Kyoto Protocol, again in 2009 G-20 Pittsburg Summit, Indonesia delivered the commitment on reducing $26 \%$ on its emission level. Moreover, as non-annex 1 country, Indonesia shows strong and bold commitment in supporting reduction on increased concentrations of greenhouse gases produced by human activities such as burning the fossil fuels and deforestation. From the energy sector, Carbon Capture and Storage (CCS) is known as a process of capturing waste carbon dioxide $\left(\mathrm{CO}_{2}\right)$ from large point sources and depositing it normally at an underground geological formation. CCS becomes now as one of the possible supports to the country commitment. In Indonesia, the potential of CCS applications could be conducted in the gas fields with high content of $\mathrm{CO}_{2}$ and in almost depleted oil fields (by applying $\mathrm{CO}_{2}$-Enchanced Oil Recovery (EOR) The CCS approach could also be conducted in order to increase hydrocarbon production, and at the same time the produced $\mathrm{CO}_{2}$ will be injected and storage it back to the earth. Thus, CCS is a mitigation process in enhancing carbon emission reduction caused by green house effect from production hydrocarbon fields.
\end{abstract}

This paper will show a proposed milestone on CCS Research roadmap, as steps to be taken in reaching the objective. The milestone consists of the study for identifying potential $\mathrm{CO}_{2}$ sources, evaluating $\mathrm{CO} 2$ storage sites, detail study related to $\mathrm{CO}_{2}$ storage selection, $\mathrm{CO}_{2}$ injection, and $\mathrm{CO}_{2}$ injection monitoring. Through these five steps, one can expect to be able to comprehend road map of CCS Research. Through this research milestone, applications of CCS should also be conducted based on the regulatory coverage milestone. From this paper, it is hoped that one can understand the upstream activities starting with research milestone to the very end downstream activities regarding to the regulation coverage bound.

Keywords: CCS, reduction of carbon emission, regulation umbrella

\section{Introduction}

The Kyoto Protocol is an international treaty that sets binding obligation on industrialized countries to reduce emissions of "Greenhouse Gases". United Nations Framework Convention on Climate Change (UNFCCC) is an environmental treaty with the goal of preventing "dangerous" such as human induced interference of the climate change system. The first commitment period applies to emissions between 2008-2012; the protocol was amended in 2012 to accommodate the second commitment period between 2013-2020, but this amendment not entered into legal force.

"Carbon Trade" based on Clean Development Mechanism (CDM) as International emissions trading allows developed country to trade their commitments, and they can trade emissions quotas among themselves, and also can receive credit for financing emissions reductions in developing countries as Indonesia ratified Kyoto Protocol. Developing countries do not having

\footnotetext{
* Corresponding Author:

Email: a_kusuma@pertamina.com
} 
binding targets under the Kyoto Protocol, but are still committed under the treaty to reduce their emissions.

Actions taken by developed and developing countries to reduce emissions include support for renewable energy, improving energy efficiency and reducing deforestation. Indonesia reflects this supports by existence of Directorate General of EBTKE (Energi

Baru Terbarukan dan Konservasi Energy or New, Renewable and Conservation Energies) within Ministry of Energy and Mineral Resources, who initiated this coming workshop in Jakarta at 21st August 2013, Jakarta .

Indonesia commitment in reducing emission through developing the renewable energy clearly stated their commitment in "Energy Nasional Policy" through Degree no 5/2006 ", further in "Energy Law" through regulation no. 30 th 2007. Indonesia Law no 6/1997 and law no 17/2004 ratified existence of UNFCCC and Kyoto Protocol, and through these laws, Indonesia as developing country legally committed, in preserve their environmental ecology, and under UN Declaration on the Rights on Indigenous Peoples enact in UU 32/2009.

A carbon footprint as defined "the total sets of greenhouse gas (GHG) emissions caused by an organization, event, product or person.", is impossible to calculate total carbon footprint due to the large amount of data required and the fact that carbon dioxide can be produced by natural occurrences. It is for this reason that Wright et. Al. (2013) have suggested a more practicable definition: "A measure of the total amount of carbon dioxide $\left(\mathrm{CO}_{2}\right)$ and methane $\left(\mathrm{CH}_{4}\right)$ emissions of a defined population, system or activity, considering all relevant sources, sinks and storage within the spatial and temporal boundary of the population, system or activity of interest. Calculated as carbon dioxide equivalent $\left(\mathrm{CO}_{2} \mathrm{e}\right)$ using the relevant 100-year global warming potential (GWP100)."

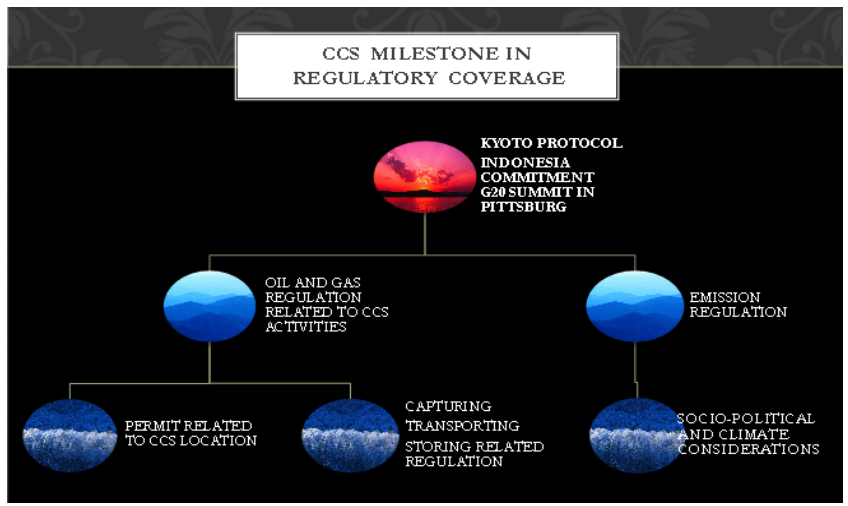

Fig. 1 CCS Milestone in regulary coverage

The mitigation of carbon footprints through the development of alternative projects, such as geothermal, hydro, solar, wind energy or reforestation represents one way of reducing a carbon footprint and is often known as Carbon Offsetting, while through Technological Development such as Carbon Capture Storage (CCS) considered as Carbon Reduction to tackle the main influences on carbon footprints include economic output, dependence of fossil energy and carbon intensity of economy.

The current situation post Kyoto Protocol first commitment, supported by technological development, the mitigation in combating the carbon reduction moved from Carbon Offsetting to Carbon Reduction, and CCS is one of tool in supporting Clean Development Mechanism (CDM).

\section{The Carbon Capture and Storage (CCS)}

Carbon capture and storage (CCS) is the process of capturing waste carbon dioxide $\left(\mathrm{CO}_{2}\right)$ from large point source such as gas production reservoir, transporting it to a storage site, and depositing it where it will not enter the atmosphere, normally an underground geological formation. The aim is a potential means of mitigating the large quantities of $\mathrm{CO} 2$ into the atmosphere, as contribution of fossil fuel emission. Although $\mathrm{CO}_{2}$ has been injected into geological formations for several decades for various purposes, including enhanced oil recovery as secondary or even further recovery, the long term storage of $\mathrm{CO}_{2}$ is a relatively new concept. The milestone study consists of:

- Identifying potential CO2 sources. Starting with identifying waste carbon dioxide (CO2) content, from large point source entering the atmosphere. 
- Mapping potential CO2 storage sites. Potential sequestration site identified and for further investigation.

- Detail study related to potential CO2 sequestration site selection, geological formation are currently considered the most promising sequestration sites, deep ocean storage is no longer considered feasible.

- Injection and storing captured $\mathrm{CO} 2$ to the chosen storage location.

- CO2 Storage Monitoring, since the liability of potential leak(s) is one of the largest barriers to large-scale CCS. To assess and reduce such liability, the leakage of stored gasses, particularly carbon dioxide into the atmosphere may be detected via atmospheric gas monitoring and quantify.

Through these five steps, one can expect to be able to comprehend road map of CCS Study. Those five main steps mentioned above, since we are in the business of handling hazardous material, for the good intention for emission reduction, in combating global warming process, regulation coverage should protect harmful, unnecessary activities related in handling these $\mathrm{CO} 2$.

Global initiatives as mentioned above, where Indonesia keep committing in combating global warming process, initiated by Kyoto Protocol continued by G-20 Pittsburg Summit, Carbon Capture Sequestration (CCS) is one of the realization on these global commitment.

Methodology, one can define as thinking method or cogito process structure or road to reach answer to the identified question or problem to be solved. Deductive normative method was use, method of inferring from general to particular is used started from the global warming is issued globally, and Kyoto Protocol was stated continue to commitment in G20 Pittsburg Summit and to the Indonesian domestic regulation set up in normative way. Methodology is the systematic, theoretical analysis of the methods applied to a field of study, or the theoretical analysis of the body of methods and principles associated with a branch of knowledge. It, typically, encompasses concepts such as paradigm, theoretical model, phases and quantitative or qualitative techniques. A Methodology does not set out to provide solutions but offers the theoretical underpinning for understanding which method, set of methods or so called "best practices" can be applied to a specific case.

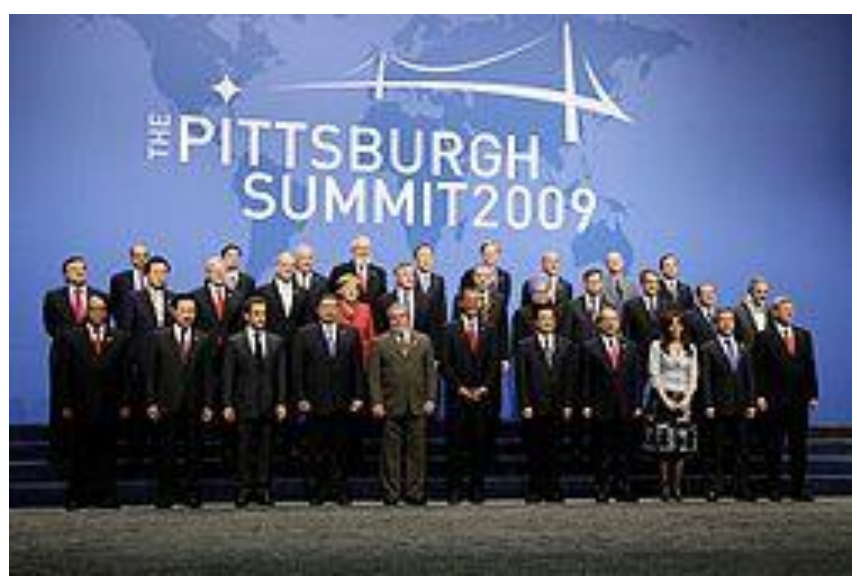

Fig. 2: The participants of the Pittsburg Summit, represented the core members of the G-20

\section{Result and Conclusion}

As non-Annex-1 country, Indonesia offered a strong and bold commitment to $26 \%$ emission redution in the G20 Pittsburg Summit, which could be supported by CCS from energy sector. Capturing $\mathrm{CO}_{2}$ is probably most effective at point sources, such as large fossil fuel industries $\mathrm{CO}_{2}$ emissions, natural gas processing. Extraction (recovery) from air is possible, but not very practical. After capture, the $\mathrm{CO}_{2}$ would have to be transported to suitable storage sites. This is done by pipeline, which is generally the cheapest form of transport.

Storage of the $\mathrm{CO}_{2}$ is envisaged either in deep geological formations, or in the form of mineral carbonate. Deep ocean storage is no longer considered feasible because it greatly increases the problem of ocean acidification. Geological formations are currently considered the most promising sequestration sites. The Indonesian 68 years developing oil and gas activities, has enough storage capacity. A general problem is that long term predictions about submarine or underground storage security are very difficult and uncertain, and there is still the risk that $\mathrm{CO}_{2}$ might leak into the atmosphere. For that monitoring system is needed. The 
pilot carbon sequestration in Gundih field, Central Java - Indonesia, is the first CCS implementation project in Indonesia, which is conducted by using the mixture between international fundings (JICA-JST and ADB) and national fundings (ITB, Pertamina, and DGHE).

The current situation post Kyoto Protocol first commitment, supported by technological development, the mitigation in combating the carbon reduction moved from Carbon Offsetting to Carbon Reduction, and CCS is one of tool in supporting Clean Development Mechanism (CDM).

\section{Acknowledgements}

We thank JICA-JST funding of SATREPS program and ADB funding for providing research grant of Pilot Study of Carbon Sequestration in Gundih field, Central Java, Indonesia, so that

\section{References}

L. A. Wright, S. Kemp, and I. Williams, 'Carbon footprinting': towards a universally accepted definition. Carbon Management, 2, (1), p. 61-72, 2011.

W. G. A. Kadir, R. Sule, S. Alawiyah, D. Santoso, D. S. Widarto, Adriansyah, R. Affandi, D. Sasongko, and T. Matsuoka, Proc. of World Renewable Energy Congress - Indonesia: International Conference on Renewable Energy and Energy Efficiency, Bali - Indonesia, 2011. 